\title{
Poetas a pie de calle: espacios para la transferencia en la noche de los investigadores.
}

\author{
$M^{\mathrm{a}}$ del Carmen Quiles Cabrera \\ qcabrera@ual.es \\ Universidad de Almería \\ Mar Campos F.-Fígares \\ mcampos@ual.es \\ Universidad de Almería \\ Aitana Martos García \\ aitmartos@gmail.com \\ Universidad de Almería
}

Fecha presentación: 20/10/2017 | Aceptación: 10/11/2017 |Publicación: 21/12/2017

\section{Resumen}

Bajo el título de este artículo planteamos una reflexión en torno a la transferencia del conocimiento en el ámbito de la educación literaria. Partimos del nuevo concepto de lectura y de lector -espacios en red, programas informáticos-, cuya evolución ha venido marcada por los cambios sociales y tecnológicos, para plantear la necesidad de acercar el hecho literario a los integrantes de cada comunidad y aproximarlos al lenguaje poético desde el juego y la experimentación. Así, describimos la iniciativa que supuso Poetas a pie de calle en la Noche Europea de los Investigadores, en tanto que modelo de transferencia desde las Humanidades y las Ciencias de la Educación.

Palabras clave: ciberpoesía, escritura creativa, nuevos lectores, transferencia del conocimiento.

\section{Resum}

Sota el títol d'aquest article plantegem una reflexió al voltant de la transferència del coneixement en l'àmbit de l'educació literària. Partim del nou concepte de lectura i de lector -espais en xarxa, programes informàtics-, l'evolució del qual ha estat marcada pels canvis socials i tecnològics, per plantejar la necessitat d'apropar el fet literari als integrants de cada comunitat i aproximar-los al llenguatge poètic des del joc i l'experimentació. Així, descrivim la iniciativa que va suposar Poetes a peu de carrer a la Nit Europea dels Investigadors, en tant que model de transferència des de les Humanitats i les Ciències de l'Educació.

Paraules clau: ciberpoesia, escriptura creativa, nous lectors, transferència del coneixement.

\section{Abstract}

Under the title of this article we propose a reflection on the transfer of knowledge in the field of literary education. We start from the new concept of reading and reader - network spaces, computer programs - whose evolution has been marked by social and technological changes, to raise the need to bring the literary fact closer to the members of each community and bring them closer to poetic language from game and experimentation. Thus, we describe the initiative that Poetas a pie de calle in the European Night of the Investigators, as a model of transference from the Humanities and the Sciences of the Education.

Key Words: digital poetry, creative writing, new readers, transfer of knowledge 
Quiles Cabrera, Ma del Carmen; Campos F.-Fígares, Mar; Martos García, Aitana. "Poetas a pie de calle: espacios para la transferencia en la noche de los investigadores”. @tic. revista d'innovació educativa. Número 19. Otoño (juliodiciembre 2017), pp. 40-46.

\section{Los espacios de la lectura en el mundo digital}

En los últimos años el concepto de lectura, así como los espacios en los que esta se manifiesta, han evolucionado a un ritmo galopante desde las páginas de los libros hasta las ondas del ciberespacio. Las nuevas generaciones son definidas como nativos digitales, que no entienden el mundo si no está vinculado de alguna forma con la tecnología digital, las redes sociales y las plataformas on line. Tanto es así que su forma de acceder a la literatura está condicionada por estos elementos. Pero también estamos siendo testigos de que este fenómeno, el acceder al conocimiento en general a través de Internet, como primera fuente de consulta, esta imponiéndose también entre los adultos. Afirma Cordón (2016) que "la aparición de un sistema de intermediación modifica radicalmente todo el ecosistema del libro (...) La mediación tecnológica introduce un elemento nuevo en el proceso lector, vinculado con la apropiación del dispositivo y con la ejecución del contenido. No basta con saber leer, sino que es preciso controlar donde se lee y, sobre todo, como se lee" (págs.250-251). Recordemos la revolución que supuso la aparición del libro electrónico, algo que fue objeto de estudio en el programa impulsado por la Fundación Germán Sánchez Ruipérez bajo el nombre de Territorio Ebook (Cordón, 2016).

Para dar cabida a este fenómeno y tratar de visibilizar al máximo las prácticas de lectura que se llevan a cabo en la universidad y sus entornos más cercanos, nuestro grupo de investigación lleva trabajando, desde hace más de una década, en el proyecto Cartografías lectoras de las universidades públicas de Andalucía (dentro del marco del Proyecto ATALAYA, financiado por la Junta de Andalucía). El primer producto cultural de dicho proyecto fue la plataforma cartografiaslectoras.com que fue pionera (y lo sigue siendo) a la hora de dar visibilidad a las mencionadas prácticas de lectura y a la hora de poner al alcance del usuario de a pie un recurso centrado en la lectura y de fácil acceso como es su disponibilidad en internet; una disponibilidad que se implementaría con la dimensión en realidad aumentada a través del teléfono móvil, mediante la aplicación GeoLAYAR ${ }^{1}$, que permite informar al usuario de los contenidos registrados en la plataforma en un radio de hasta 5 kilómetros con respecto a su situación en el momento de la consulta. La plataforma está abierta a las sugerencias de los usuarios que quieran proponer la inclusión de nuevos contenidos.

La gran eficacia que el recurso representó (y representa) ante la necesidad de acercar a los jóvenes universitarios a la lectura (y a la literatura en general) nos llevó a observar los derroteros por los que se movían nuestros estudiantes en el ámbito de la lectura literaria. Es un hecho que la web ha supuesto un cauce muy frecuente de difusión de obras, de intercambio de experiencias lectoras, en definitiva, de acceso a la lectura y también a la escritura. Cuando en 2009 Martos García iniciaba sus estudios en torno a las sagas, la cibercultura y la fanfiction, por ejemplo, empezábamos a ser conscientes de que, en la actualidad, muchos de nuestros estudiantes son usuarios habituales de páginas como fanfict.net, aunque con frecuencia no lo reconocian

\footnotetext{
${ }^{1}$ De este proyecto se derivó la publicación Cartografías lectoras y otros estudios de lectura (2014), y fue presentado por nuestro grupo de investigación en la Noche de los Investigadores del año 2014
}

públicamente. Y de que son esas páginas, precisamente, no sólo lugares para la difusión, sino también para la creación de textos. Desde entonces se sucedieron diversos trabajos sobre este tipo de literatura entre los que destacan las aportaciones de Encabo, Urraco y Martos (2016), trabajos que han permitido "legitimar" ante el público en general el interés de los más jóvenes lo que hasta hace poco tiempo podían ser consideradas como prácticas "menores".

$Y$ otro de los elementos que sin duda ha experimentado un cambio muy drástico ha sido el de los mediadores entre las obras y los lectores. Al mediador clásico -la familia, el maestro, el bibliotecario- se le ha sumado, poniéndose al mismo nivel o incluso, según las ocasiones, muy por encima, el bloguero. Que bien puede ser alguno de los agentes citados, que ofrecen su mediación en estos soportes, o bien lectores espontáneos, jóvenes o adolescentes cuyo ámbito de influencia no pasaría hace algunos años de su entorno más cercano para convertirse ahora en agentes buscados por las editoriales para influir en los potenciales lectores de determinadas obras. EI fenómeno no ha pasado desapercibido y Sánchez García, Lluch y Del Río Toledo (2012) en su estudio acerca del impacto que había tenido la iniciativa publicitaria de una conocida editoral que, en el año 2011 proporcionó a determinados blogueros la posibilidad de leer una obra de literatura juvenil un día antes de su lanzamiento al mercado. En correspondencia a este "privilegio" los blogueros colgarían inmediatamente sus comentarios, convirtiéndose en agentes muy activos de mediación y difusión de la obra publicada.

De la misma forma sucede con plataformas diversas que se han establecido como nuevos espacios privilegiados de mediación, como los canales de Youtube, donde han surgido los llamados booktriler o bibliotriler, por ejemplo, un género discursivo de mediación que está haciendo más corto el camino entre los jóvenes y la lectura, trasladando un recurso de la publicidad del cine a la publicidad de las obras literarias.

Se suceden prácticas híbridas en las que los límites entre unas artes y otras se diluyen, apoyándose mutuamente en creaciones nuevas que parecen satisfacer más a los jóvenes que las tradicionales. Es en este contexto de prácticas heterogéneas, entre la literatura y las TIC donde surge la ciberliteratura, "una nueva forma de entender lo literario a partir de las posibilidades tecnológicas abiertas por el desarrollo tecnológico digital" (Morales, 2013, p.96), entorno fuera del cual es imposible acceder a ella.

Es bien sabido que el marco de la experimentación con la literatura y otras artes se remonta a tiempos muy antiguos, aunque sin irnos tan lejos podemos retrotraernos a las Vanguardias y su entusiasmo por la experimentación en la combinación de distintas artes para alcanzar la creación máxima. Este movimiento venía emparentado con el juego, con el uso de las palabras como herramienta lúdica, de ahí su vinculación con la infancia, con el deseo del niño por descubrir y divertirse. En el ámbito escolar la pintura surrealista de Joan Miró, por ejemplo, cuenta con gran éxito y es un modo de acercarnos a la pintura como arte. De igual forma ocurre con la vanguardia en literatura, especialmente cuando hablamos de creación. Carlos Edmundo de Ory, poeta postista, dejó bien claro el paralelismo entre su poesía y la vuelta a la infancia. Así, cuando hablamos de crear poesía visual estamos 
Quiles Cabrera, $M^{a}$ del Carmen; Campos F.-Fígares, Mar; Martos García, Aitana. "Poetas a pie de calle: espacios para la transferencia en la noche de los investigadores". @tic. revista d'innovació educativa. Número 19. Otoño (juliodiciembre 2017), pp. 40-46.

llevando a los aprendices a una experimentación que los va a divertir al tiempo que entran en contacto con el sentir poético y el uso de las palabras como creación de arte. Nadie representa mejor la poesía visual que el autor Joan Brossa. Y nos interesa especialmente el Fotopoemario que publicó junto al fotógrafo Chema Madoz; a partir de doce fotografías tomadas por éste, Brossa construyó doce poemas visuales representativos de este ámbito. Afirma Kika Beneyto que "Fotopoemario está compuesto por doce fotografías y doce poemas entrelazados unos con otros. Fotografías y poemas que no tienen la función de ilustrar nada, sino de acompañarse mutuamente y ofrecer una lectura distinta gracias a la cercanía" (Beneyto, 2012, p. 479).

Cuando intervienen en la partida los actuales medios tecnológicos, que nos permiten dar un paso más allá y experimentar el ámbito audiovisual, cuando hablamos de conceptos como Vídeopoema o Ciberpoesía, el referente artístico inexcusable es la figura de Joan Brossa y de todos aquellos que, como él, experimentaron con la creación poética. La tecnología, a día de hoy, nos permite ahondar en esa experimentación y llegar a otros espacios, soportes y elementos como la voz, el movimiento de la imagen y la combinación de los sentidos. Para conocer más sobre la significación de la poesía visual puede consultarse el trabajo de Laura López (2008).

\section{Integración de las TIC para la creación literaria}

El juego, pues, de las prácticas sinestésicas no es nuevo. Pero sí lo es la facilidad que las TIC nos han proporcionado para extender esta práctica con resultados satisfactorios a un amplísimo número de creadores en potencia que pueden encontrar un nuevo género altamente satisfactorio, no solo como lectores (o espectadores) o como autores, sino también como mediadores. Para estos últimos resultan de gran ayuda páginas en las que los escolares (o aprendices en general) pueden participar de forma activa en la elaboración de una historia, como es el caso de dos portales como los siguientes:

* Hipercuentos, disponible en

http://win.memcat.org/infantil/interact/hipercue/index. html

* Robotype, disponible en

http://www.robotype.net/cuento_robotype/cuento.htm

* Dictation, disponible en https://dictation.io/, que nos permite convertir la voz en texto, esto es, narramos una historia y el propio programa nos transcribe por escrito la historia.

Ahora bien, si damos un paso más allá, lo cual es en definitiva lo que nos interesa por su novedad y efectividad para el fomento de las prácticas de escritura creativa entre un usuario multimodal y nativo digital, hemos de volver la vista a programas y medios técnicos creados para la realización de composiciones literarias experimentales muy diversas, que caminen entre la poesía visual y la ciberpoesía. Veamos algunos ejemplos:

a) Medios que nos permiten jugar con el lenguaje y dar forma literal a los textos, ya que son procesadores para la elaboración de pictogramas, caligramas o poemas visuales.

* Pictotraductor, disponible en

https://www.pictotraductor.com/

* ConnectAbility, disponible en

https://connectability.ca/visuals-engine/template-with-4- boxes-per-page/\#content

* Nubedepalabras, disponible en https://www.nubedepalabras.es/

* Wordart, disponible en https://wordart.com/create

* ABCYA, disponible en http://www.abcya.com/word clouds.htm

b) Otros de estos recursos permiten la conjunción de texto, imagen, música y voz en off. Podemos mencionar los siguientes:

MiniMovie, disponible en

http://www.portalprogramas.com/minimovieedic-videopresentac/android/descargar

MovieMaker, disponible en

https://filmora.wondershare.es/editor-de-video/ad-

filmora.html?gclid=EAlalQobChMI9unG002W1wIVZrftCh 2EFgNZEAAYAiAAEgK2dfD BwE

PhotoStage, disponible en

https://photostage.softonic.com/descargar

Animoto Vídeo Maker, disponible en

https://animoto.com/k/video-

slideshow?gclid=EAlalQobChMlsvWT9-

2W1wIVb7ftCh1BBgK5EAAYASAAEgKaFvD_BwE\&utm_so urce=google\&utm medium $=$ cpc\&utm campaign $=$ GENER AL---Animoto-brand---CON-T1-

(RLSA)\&utm term=animot\&utm content $=$ brand\&ef $i d=V$ 3w2MQAAAdIR4STJ:20171029221627:s

Veditor, disponible en

https://www.appannie.com/en/apps/ios/app/veditoreditor-de-video-anadir-filtros-texto-musica-efectos-desonido-imagenes-y-pegatinas/\#

KineMaster, disponible en

https://kinemaster.uptodown.com/android

VideoSpin, disponible en https://pinnacle-

videospin.uptodown.com/windows

Filmora, disponible en https://filmora.wondershare.es/

Avidemux, disponible en

https://avidemux.uptodown.com/windows

VideoPad, disponible en https://videopad-videoeditor.softonic.com/

\section{El marco de La Noche Europea de los Investigadores}

La Noche Europea de los Investigadores es un proyecto europeo de divulgación científica 2 que se viene desarrollando como un espacio para el intercambio y la difusión del conocimiento emanado desde las universidades, con el objetivo de presentar a los investigadores y sus intereses de estudio al público en general, en la calle, como una actividad lúdica que permite visibilizar ante toda la sociedad el sentido de tales estudios en la vida cotidiana. Al principio esta confluencia de grupos de investigación se asociaba al ámbito tecnológico o clínico, reduciendo la idea de "mujeres y hombres que hacen ciencia para ti" a un número limitado de áreas o líneas de trabajo. Sin embargo, el evento muy pronto dio cabida a todos aquellos grupos que, desde las Humanidades y las Ciencias de las Educación, vienen haciendo esa ciencia emparentada con el ámbito humano y social. Lo que comenzó como transferencia de la tecnología pronto se

\footnotetext{
2 Programa promovido por la Comisión Europea en el marco de las acciones Marie Sktodowska-Curie (programa Horizonte 2020). Participan en el mismo más de 300 ciudades europeas (30 países) que organizan La Noche de manera simultánea. En el caso de Almería se lleva participando de manera ininterrumpida desde el año 2012.
} 
Quiles Cabrera, Ma del Carmen; Campos F.-Fígares, Mar; Martos García, Aitana. "Poetas a pie de calle: espacios para la transferencia en la noche de los investigadores”. @tic. revista d'innovació educativa. Número 19. Otoño (juliodiciembre 2017), pp. 40-46.

denominaría transferencia del conocimiento, porque se estaba dando cabida a disciplinas de otra naturaleza (Castro, Fernández, Pérez y Criado, 2008). El concepto de "ciencia" ha de ser entendido en su sentido pleno y esto es algo que se ha logrado poner de manifiesto y hacer visible ante la sociedad gracias a iniciativas como La Noche europea de los investigadores. En este sentido, nuestro grupo de investigación (CEOM) desde muy pronto tuvo clara presencia activa en este evento, dada la esencialidad que nuestras investigaciones adquieren en esa propuesta de transferencia del conocimiento. Si lo que se pretende es que la Universidad y sus hallazgos adquieran realmente un calado social y contribuyan a cambiar el presente, a mejorar la existencia y a construir un futuro más próspero, la labor de quienes nos dedicamos a la formación lingüística y literaria es de vital importancia. La lectura como eje para conformar el pensamiento, para desarrollar una conciencia crítica y para abrir caminos a la reflexión, la convierten en abanderada para el acceso a todos los aprendizajes. Se trata, por tanto, de una destreza que no sólo ha de ocupar el centro en las aulas de todos los niveles educativos, sino que ha de traspasar todas las barreras y entenderse como un agente social para el cambio. La lectura - y la escritura- forman parte de la vida de los ciudadanos de a pie, que viven inmersos en una sociedad letrada donde el código está por todas partes. Por eso, la literatura debiera ponerse a su alcance en esos otros espacios que se frecuentan cada día en los entornos cotidianos: las paradas de autobús o de metro, los cafés, los parques, etc. Llevar a La Noche de los Investigadores esta inquietud y establecer un contacto real del gran público -infantil y adulto- con los libros, el sentir poético y la experimentación de la escritura en espacios interactivos fue algo que comenzó siendo un reto y que acabó como una experiencia única que demuestra que todos los espacios son espacios para la lectura y la creación literaria.

\section{La idea de Poetas a pie de calle como transferencia del conocimiento}

Las nuevas prácticas docentes materializan los resultados de la investigación en innovación docente y, en este caso, nos llevan fuera del aula para dar visibilidad a las múltiples posibilidades que ofrecen la poesía visual y el ciberespacio para el ámbito de la educación literaria ${ }^{3}$. El objetivo general del presente artículo es la descripción de esta propuesta que fue llevada al espacio descrito anteriormente, La Noche, para poner en conocimiento de la ciudadanía las figuras destacas del momento con una muestra real e in situ de sus creaciones poéticas. Esto es una forma de poner a los poetas a pie de calle y de entender que hoy día esa calle no solo existe en el asfalto sino también en la pantalla de nuestro ordenador. Elvira Sastre ${ }^{4}$, Sara Búho ${ }^{5}$ o Loreto Sesma ${ }^{6}$ son buenos ejemplos de esta

\footnotetext{
3 Para esta iniciativa se contó con el apoyo de La Red Internacional de Universidades Lectoras y de la Fundación Cultural Miguel Hernández.

4 Para más información sobre esta autora, consúltese http://elvirasastre.net/poemas/ (página visitada el 21 de octubre de 2017)

5 Pueden verse algunas de sus creaciones en http://sarabuho.blogspot.com.es/ (consultada el 21 de octubre de 2017).
}

nueva forma de la poesía contemporánea. Si desde nuestro ámbito en la universidad -la formación de maestros y educadores sociales- perseguimos una formación de lectores eficaz que los capacite para ser mediadores en lectura, es imprescindible partir de un concepto de lector que lo es no sólo en los límites del aula, sino en su día a día habitual. Dicha premisa no se logra si no se transfiere desde la propia práctica y experimentación.

Ahora bien, fue nuestra intención, en la línea de lo que venimos planteando, fue dar un paso más y hacer del espectador (el lector) parte implicada en el proceso de creación. De ahí la actividad que propusimos como "De la poesía visual a la ciberpoesía" 7 . Los transeúntes fueron invitados a producir sus propios textos con un montaje de imagen, audio y texto que, junto con el de otros usuarios, conformaron un corpus poético nacido de la experimentación, al modo en que, como mencionábamos supra, las vanguardias entendieron el hecho literario. Podemos decir que "esto entra en consonancia con las nuevas manifestaciones de la poesía on line, creadas a través de aplicaciones o programas informáticos que, al mismo tiempo, pueden convertir a los lectores en creadores de textos poéticos en formato digital" (Quiles, 2016: 10). Contamos, además, con la autora Raquel Cabest 8 , una de las poetas más significativas del momento en este género. Palabra, imagen, sensibilidad y tecnología se dieron la mano de una forma constructiva y pedagógica en un espacio muy diferente al marcado por los límites de un aula.

\section{Descripción del taller \\ 5.1 El espacio y el tiempo}

El taller fue realizado en plena calle, en una de las avenidas principales de la ciudad de Almería. Se desarrolló a lo largo de cinco horas ininterrumpidas durante la tarde-noche del evento internacional: Noche Europea de los Investigadores.

\subsection{Los participantes}

Dada la naturaleza del evento, los participantes estuvieron sujetos al azar, no obedecieron a ningún criterio en concreto más allá del mero interés que fue suscitando la actividad propuesta entre los transeúntes. Al tratarse de un espacio compartido con el resto de grupos de investigación, los usuarios implicados fueron aquéllos que se acercaron a nuestros paneles y

\footnotetext{
${ }^{6}$ Consúltese https://es-es.facebook.com/Loreto-Sesma1465773687017016/ (página visitada el 21 de octubre de 2017).

${ }^{7}$ Además, contamos con la colaboración de la Biblioteca Municipal de Berja, representada por Rocío Domínguez y el artista visual Francisco Escudero, quien dirige los talleres de poesía visual en dicho centro. El grupo de investigación CEOM cuenta con una vinculación muy estrecha con la Biblioteca pública de este municipio almeriense, desde que se firmara el acuerdo de colaboración dentro del marco institucional del programa Intrecambio Empresa-Universidad, que viene renovándose desde hace casi una década. En este sentido, recomendamos consultar información sobre el Festival de Poesía Visual de Berja (disponible en http://www.diariodealmeria.es/ocio/Berja-Festival-PoesiaVisual-Criado 0 1119488536.html)

8 Puede accederse a algunas de sus obras en https://www.youtube.com/watch?v=LOwdTpS83RY (consultada el 30 de octubre de 2017)
} 
Quiles Cabrera, $M^{a}$ del Carmen; Campos F.-Fígares, Mar; Martos García, Aitana. "Poetas a pie de calle: espacios para la transferencia en la noche de los investigadores". @tic. revista d'innovació educativa. Número 19. Otoño (juliodiciembre 2017), pp. 40-46.

manifestaron su interés por participar, un interés que fue masivo y muy diverso. Así, contamos con la participación de creadores de ambos géneros y edades muy variadas, lo cual enriqueció sin duda la tarea experimental.

\subsection{Materiales}

Además de los recursos humanos, disponíamos de dos mesas, varios paneles, material de escritorio (hojas para anotar, papel continuo, bolígrafos, un corcho), dos ordenadores, un cañón proyector y una caja con objetos diversos.

\subsection{Desarrollo del taller}

El taller dio comienzo con la proyección de poesía visual y vídeopoemas de autores experimentados en este ámbito, de manera que los viandantes tenían un contacto directo con este tipo de expresión. La presencia de la poeta Raquel Cabest hacía más efectivo el impacto, puesto que pudo establecerse el feed back con muchos de los interesados. A medida en que los usuarios se fueron convirtiendo en participantes, el taller se focalizó en tres direcciones:

a) La poesía visual y el juego con el lenguaje poético.

Para ello utilizamos la conocida técnica de la que ya hablara Gianni Rodari en La caja de la fantasía, pero combinada con el uso de programas de ordenador que nos permitieron acercar la escritura a un nuevo perfil de lector -y de escritor-. En este caso, una caja de cartón escondía distintos objetos que, sacados al azar, le darían a cada participante el motivo sobre el cual escribir un pequeño texto poético. Tales composiciones oscilaron desde evocaciones poéticas sencillas hasta haikus o poemas extensos. Todas ellas, escritas sobre el papel en un principio fueron convertidas en poemas visuales, caligramas, pictogramas o en lo que podríamos llamar textos híbridos, ayudados por programas como los mencionados previamente.

Véanse los siguientes ejemplos:

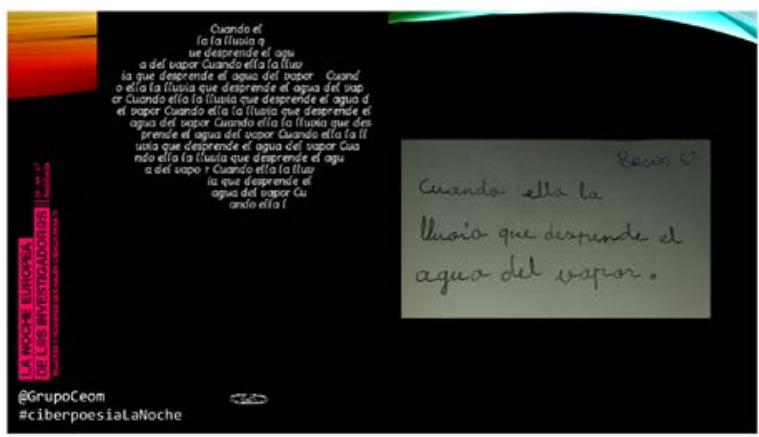

Figura 1. Elaboración propia.

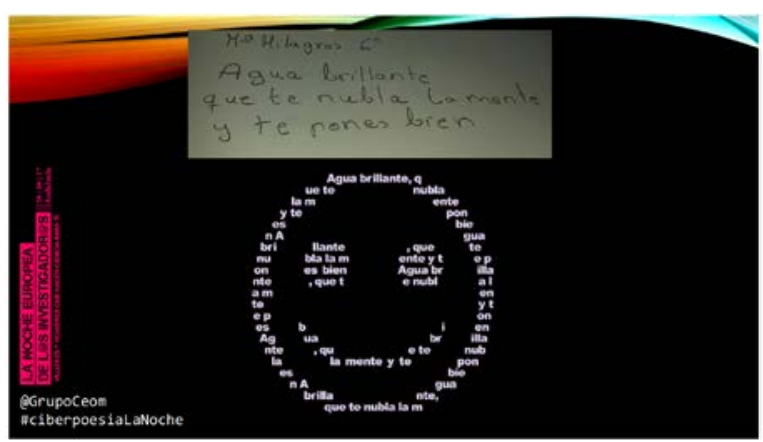

Figura 2. Elaboración propia. b) La videopoesía.

Otras de las composiciones que los participantes escribieron, fueron convertidas en ese mismo momento en viodeopoemas, elaborados in situ por los propios autores. Los participantes fueron parte activa no sólo en la elaboración técnica, sino también a la hora del recitado. Usamos el programa PHOTO STAGE 9 , que nos permite editar las imágenes seleccionadas con el texto del poema, al tiempo que grabar la voz en off de cada protagonista. El resultado final es un videopoema que ha nacido de un ejercicio de escritura creativa en un espacio poco convencional y que está marcado por la experimentación y la espontaneidad de un intercambio de experiencias lectoras. Veamos un ejemplo compuesto por dos fotogramas (la voz en off está recitada en el texto original por la propia autora) a partir de la evocación:

"Besos de fresa rotos... Ahora los coso por las esquinas".
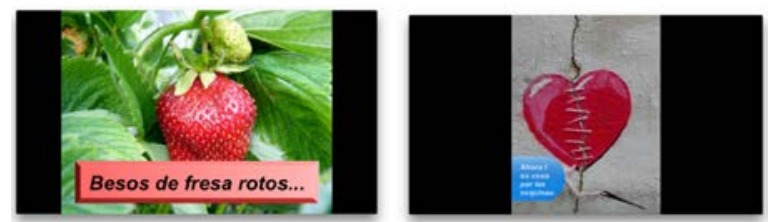

Figura 3. Elaboración propia con uso de imágenes de acceso libre.

Otro buen ejemplo es la composición de una niña de sexto de primaria, que se recogió en tres fotogramas (con la voz en off):

\section{"La lluvia hace \\ un baile de agua. \\ ¡Ay, victorioso!”}

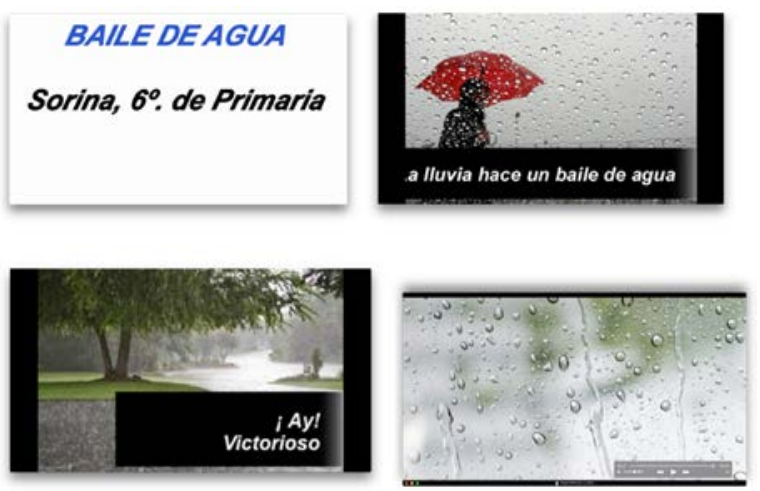

Figura 4. Elaboración propia con uso de imágenes de acceso libre.

c) Otros montajes poéticos.

Mediante programas muy conocidos como el Power Point los usuarios realizaron montajes donde el lenguaje poético era el protagonista. La posibilidad que nos ofrece esta herramienta de grabar archivos de audio hizo posible insertar en la composición la voz de los autores bajo el icono de sonido.

9 Descarga gratuita de prueba en

https://photostageslideshowmakerfreeformac.softonic.com/ma c/descargar (visitada el 21 de octubre de 2017) 
Quiles Cabrera, $M^{a}$ del Carmen; Campos F.-Fígares, Mar; Martos García, Aitana. "Poetas a pie de calle: espacios para la transferencia en la noche de los investigadores". @tic. revista d'innovació educativa. Número 19. Otoño (juliodiciembre 2017), pp. 40-46.

Nos sirven los siguientes ejemplos para ilustrar el resultado:

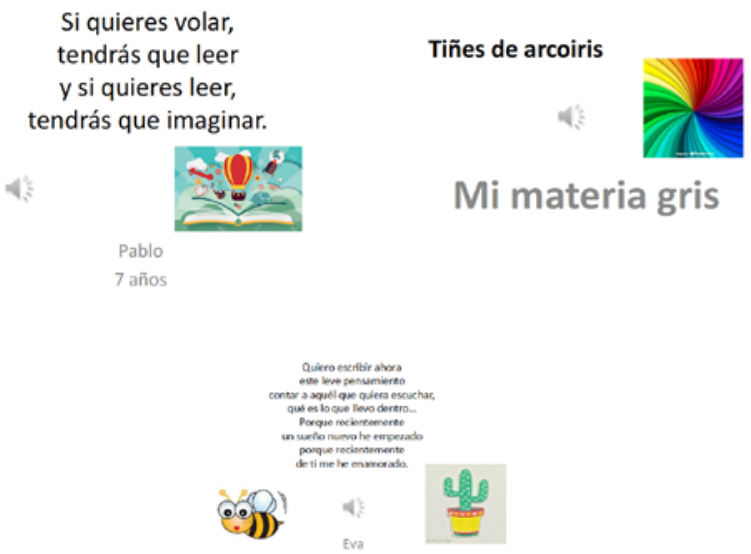

Figura 5. Elaboración propia con uso de imágenes de acceso libre.

d) Creación de un Canal de Youtube.

La idea fue garantizar una difusión lo más amplia posible de las producciones creadas en La Noche por la ciudadanía, que se acabó convirtiendo en participante activa. Así, abrimos en YOUTUBE un canal con el título "ciberpoesía", al que se fueron subiendo las aportaciones y donde pueden encontrarse todavía para su visualización. La subida de textos se comenzó a realizar en el propio acto, así como en días sucesivos, dando cabida a muchos más textos que nos llegaron a través de nuestro correo electrónico también creado para la ocasión: ciberpoesiaceom@gmail.com.

El enlace directo del canal es https://www.youtube.com/channel/UCdsJEJTeYIiXnMYqJZbZdg

\section{Conclusión}

Poetas a pie de calle fue una iniciativa muy productiva y de gran impacto en la sociedad almeriense, pues consiguió transferir las investigaciones en torno a las nuevas formas de expresión literaria a la ciudadanía que, muchas veces, se siente alejada de la lectura. Fue una manera de hacerla consciente de que todos somos lectores y de que el paso hacia la lectura literaria es muy sencillo; incluso el ámbito de la creación. Cuando sentimos el miedo al papel en blanco, la experimentación y el juego nos ayudan a despojarnos de los prejuicios e inseguridades y nos permite construir belleza con las palabras y el sentimiento poético. Si, además, contamos con medios técnicos que nos abren múltiples posibilidades, conectaremos mucho mejor con esa comunidad de nativos digitales habituada a comunicarse a través de los espacios en red. Incluso para el inmigrante digital, esto es, para toda esa generación que se ha visto asaltada por las tecnologías de la información y se ha ido amoldando a sus usos diversos, el campo de la ciberpoesía presenta un gran atractivo y lo aproxima a un terreno que les parecía muy lejano. El taller vino a acortar distancias, a demostrar que la idea elitista de la creación poética, que pareciera estar reservada para unos pocos, no es del todo cierta, porque en realidad está al alcance de todos; porque al experimentar el juego con las palabras llegamos a entender mejor el mensaje del poeta y su forma de percibir la realidad.

\section{Bibliografía}

Beneyto, K. (2012). Terrenos compartidos en la obra de Joan Brossa y Chema Madoz. Espacio, tiempo y forma, Serie VII, $H^{a}$. Del Arte, 25, pp.475-492. http://espacio.uned.es/fez/eserv.php?pid=bibliuned:ETFS erieVII-2012-25-1110\&dsID=Documento.pdf

Campos F.-Figueres M. y E. Martos (Coords.) (2014). Cartografías lectoras y otros estudios de lectura. Madrid: Marcial Pons.

Castro, E., I. Fernández, M. Pérez y F. Criado (2008). "La transferencia de conocimientos desde las humanidades: posibilidades y características". Arbor. Ciencia, pensamiento y cultura, 732, pp.619-636.

http://dx.doi.org/10.3989/arbor.2008.i732.211

Cordón, J.A. (2016). "La lectura digital y la formación del lector digital en España: la actividad de la Fundación Germán Sánchez Ruipérez y el Proyecto Territorio Ebook". Álabe. Revista de estudios de lectura y escritura, 13. http://dx.doi.org/10.15645/Alabe2016.13.11

Cordón, J.A. (2016). "La investigación sobre lectura en el entorno digital". Métodos de información, 7,13, pp.247-268. https://doi.org/10.5557/mei.v7i13.821

Encabo, E., M. Urraco y A. Martos (Coords (2016). Sagas, distopías y transmedia. León, Marcial Pons y Universidad de León.

López, L. (2008). "Forma, función y significación en poesía visual". Tonos digital: revista electrónica de estudios filológicos, 16. http://www.tonosdigital.com/ojs/index.php/tonos/art icle/view/235/177

Martos, A. (2009). "Tecnologías de la Palabra en la era digital: de la cultura letrada a la cibercultura". Revista Latinoamericana de Tecnología Educativa - RELATEC, 8 (2), pp.15-37. http://campusvirtual.unex.es/cala/editio/

Martos, A. (2009). "Sagas y fan fiction. Escritura literaria y cultura juvenil". Lenguaje y textos, 29, pp.167-175.

Quiles, Ma.C. (2016). "La poesía, ¿pasada de moda?: el lector infantil y juvenil entre el libro y el ciberespacio". EntreRíos. Revista de Arte y Letras, 25-26, pp.7-13. 
Quiles Cabrera, Ma del Carmen; Campos F.-Fígares, Mar; Martos García, Aitana. "Poetas a pie de calle: espacios para la transferencia en la noche de los investigadores". @tic. revista d'innovació educativa. Número 19. Otoño (juliodiciembre 2017), pp. 40-46.

Sánchez García, S., Lluch Crespo, G., y Del Río

Toledo, T. (2012). "Reading on Web 2.0. A Case

Study: Blogs in 'Reto Delirium"'. @tic. revista d'innovació educativa, $\quad 0(10)$, 75-84. doi:http://dx.doi.org/10.7203/attic.10.1783

| Cita recomendada de este artículo

Quiles Cabrera, Ma del Carmen; Campos F.-Fígares, Mar; Martos García, Aitana. (2017). "Poetas a pie de calle: espacios para la transferencia en la noche de los investigadores”. en @tic. revista d'innovació educativa. Número 19. Otoño (Julio-Diciembre 2017), pp. 40-46. 